\title{
Prevalence of allergen sensitization in 1000 adults in Saskatchewan
}

\author{
Stacey D. Lok ${ }^{1}$, Beth E. Davis ${ }^{1,2}$ and Donald W. Cockcroft ${ }^{1,2^{*}}$
}

\begin{abstract}
Background: The prevalence of sensitization varies geographically based on multiple environmental factors including humidity. The aim of this study was to determine the prevalence of atopy in symptomatic adults. More importantly we aimed to obtain a regional statistic of sensitization to common allergens given Saskatchewan's dry climate.

Methods: One thousand consecutive symptomatic adults were screened for atopy via skin prick test over 10 years (2006-2016) in the Division of Respirology. An atopic screen was performed with twenty common aeroallergens by a single investigator, Dr. D. Cockcroft. A positive test was considered to be a wheal $\geq 3 \mathrm{~mm}$ and markedly positive reactions $\geq 8 \mathrm{~mm}$ were also documented.
\end{abstract}

Results: The prevalence of atopy by means of a positive skin test ( $\geq 3 \mathrm{~mm}$ ) was $45.5 \%$. The prevalence of one or more markedly positive reactions ( $\geq 8 \mathrm{~mm}$ ) was $29.5 \%$ of the total population. The most frequent sensitization was to cat dander (58.2\%), followed by mixed grass (32.1\%), and birch (26.8\%). Dust mite sensitization was $22.4 \%$ and mouse 6.2\%. A positive epidemiology screen for cat/grass/mite would have incorporated $82.0 \%$ ( $n=373$ ) of subjects with positive skin tests. Those who failed the cat/grass/mite screen were mainly sensitized to trees $(n=34)$, molds $(n=22)$, weeds $(n=7)$, and animals $(n=8)$.

Conclusions: There is a high prevalence of cat sensitization in Saskatchewan, much higher than recorded in other centers internationally. This is likely due to a high proportion of cat ownership. The prevalence of mite sensitization is lower than those mentioned at other centres likely due to Saskatchewan's dry climate. The significance of the rate of markedly positive reactions ( $\geq 8 \mathrm{~mm}$ wheal) when compared to humid areas with higher burden of mite is unknown. There is a low prevalence of roach also likely due to the dry climate and mouse sensitization was low but still identified as a significant indoor allergen. A cat/grass/mite screen may be useful with a $82.0 \%$ sensitivity.

Keywords: Hypersensitivity, Asthma, Skin tests, Epidemiology

\section{Background}

Allergen sensitization varies according to multiple environmental factors including humidity [1]. The purpose of this study was to gain an appreciation of the prevalence of atopy in symptomatic patients in Saskatchewan and develop a regional statistic of common allergens in Saskatoon and the surrounding area. It was hypothesized that our allergen prevalence may differ from other regions based on our dry climate and sensitization to dust mite and roach may be

\footnotetext{
*Correspondence: don.cockcroft@usask.ca

${ }^{2}$ Division of Respirology, Critical Care and Sleep Medicine, Department of Medicine, University of Saskatchewan, 5th Floor Ellis Hall, 103 Hospital Drive, Saskatoon, SK S7N OW8, Canada

Full list of author information is available at the end of the article
}

lower for this reason. Based on previous studies performed in Saskatchewan the prevalence of atopy in the general population was observed in $38.3 \%$ ( $\geq 3 \mathrm{~mm}$ wheal) [2]. The prevalence of markedly positive reactions $(\geq 8 \mathrm{~mm}$ wheal) is also of interest as it has not been previously studied in our region and may have a bearing on severity of disease. A proposed cat/grass/mite screen [3] was also assessed to determine the utility in using these three skin tests as a screen for detecting atopy in our population.

\section{Methods}

One thousand consecutive skin prick test panels (Table 1) were collected from the years 2006-2016 on primarily adult patients. The concentration of the allergen, the allergen itself, and the supplier remained unchanged 
Table 1 Skin test allergen concentrations and contents

\begin{tabular}{ll}
\hline Aspergillus & $1: 10$ equal parts niger/terreus/repens/oryzae \\
Cladosporium & $1: 10$ \\
Dreshslera & $1: 10$ \\
Alternaria & $1: 10$ \\
Birch & $1: 20$ \\
Manitoba Maple & $1: 20$ \\
Mixed grass & $100,000 \mathrm{BAU} / \mathrm{mL}$ \\
Mixed weeds & $1: 20$ \\
Poplar & $1: 20$ \\
Ragweed & $1: 20$ \\
Willow & $1: 20$ \\
Wheat dust & $1: 10$ \\
Cat & $10,000 \mathrm{BAU} / \mathrm{mL}$ cat pelt extract \\
Cattle & $1: 20$ \\
Dog & $1: 20$ \\
Horse & $1: 20$ \\
Mouse & $1: 20$ \\
House dust mite & $5000 \mathrm{AU} / \mathrm{mL}$, equal parts Der p/Der f \\
Cockroach & $1: 20 \mathrm{two}$ equal parts American/German roach \\
Feathers & $1: 20$ equal parts chicken/duck/goose \\
Control & sodium chloride 0.9\% glycerine $50 \%$ \\
Histamine & $1 \mathrm{mg} / \mathrm{mL}$ base, 2.75 mg/mL phosphate, glycerine \\
& $50 \%$ \\
\hline
\end{tabular}

Allergens were purchased from ALK Abello. ALK Pharmaceuticals Inc, Mississuga, Ontario

Der $p$ Dermatophagoides pteronyssinus, Der $f$ Dermatophagoides farina

throughout this time period. All testing was performed by a single investigator, Dr. D. Cockcroft using the epicutaneous technique on the volar surface of the forearm with a Hollister Stier Lancet (\#8372ZA, purchased from Jubilant Hollister Stier 3525 N Regal St, Spokane, WA 99207, USA) at the Royal University Hospital in patients with symptoms suggestive of atopy, rhinitis, or asthma (Table 2). Data were collected including age, gender, and symptoms of cough, dyspnea, rhinitis. Any patients with an underlying diagnosis of $\mathrm{CF} /$ bronchiectasis and asthma were recorded. A protocol of twenty common aeroallergens (Table 1) were used as well as a negative control (sodium chloride $0.9 \% /$ glycerine $50 \%$ ) and a positive control (histamine $1 \mathrm{mg} / \mathrm{mL}$ base, $2.75 \mathrm{mg} / \mathrm{mL}$ phosphate, glycerine $50 \%$ ). A positive skin prick test was considered to be $\geq 3 \mathrm{~mm}$ wheal larger than any reaction to the negative control and markedly positive reactions as $\geq 8 \mathrm{~mm}$. One or more positives using a hypothetical 3 skin test epidemiology screen (cat/grass/mite) was also documented.

\section{Results}

After analyzing skin tests in 1000 individuals, 455 patients $(45.5 \%)$ were determined to be atopic (one or more skin wheal $\geq 3 \mathrm{~mm}$ ). Of these 1000 patients, 295 (29.5\%) had one or more markedly positive tests with wheals measuring $\geq 8 \mathrm{~mm}$. The remainder of the 545 tests yielded 515 negative skin tests, 24 with no response to histamine and 5 with dermatographisms and no positives.

The mean age of the total population was 46.5 years, with a mean age of 41.5 years in the atopic, and 50.6 years in the non-atopic patients. Females accounted for $56.7 \%$ of population with $55.4 \%$ of the atopic and $57.8 \%$ of the non-atopic population being female. The primary diagnosis and reason for testing in the 1000 individuals with descending order of prevalence was asthma, isolated cough, dyspnea not yet diagnosed, rhinitis, and cystic fibrosis/bronchiectasis.

The frequencies of positive $(\geq 3 \mathrm{~mm})$ and markedly positive $(\geq 8 \mathrm{~mm})$ skin tests in the 455 atopic patients are shown in Fig. 1. The most frequent sensitization was cat dander (58.2\%), followed by mixed grass (32.1\%), and birch (26.8\%). Dust mite sensitization was found in $22.4 \%$ and mouse in $6.2 \%$.

A positive epidemiology screen for cat/grass/mite would have incorporated $82.0 \%(\mathrm{n}=373)$ of positive skin tests. Those with negative cat/grass/mite responses showed positive responses to trees $(\mathrm{n}=34)$, molds $(\mathrm{n}=22)$, weeds $(\mathrm{n}=7)$, animals $(\mathrm{n}=8)$, cockroach $(\mathrm{n}=5)$, and feathers $(\mathrm{n}=1)$.

\section{Discussion}

The primary objective of this study was an epidemiological surveillance of the prevalence of sensitization in symptomatic adults in the Saskatoon region. Given the large sample size and collection of data from ten consecutive years, an appropriate sample was felt to be achieved. Some limitations to the sample included the data of rural or urban location of the patient was not collected. Given environment is an important contributor to sensitization profiles [1] this information may have been of interest.

One of the most intriguing components to our results was the extremely high rates of cat sensitization in our sample. Sensitization to cat was found in $58.2 \%$ of individuals with positive skin prick tests. When comparing this to other studies the rates found were $17.7 \%$ in a journal from Chile [4] and 24.3\% from a cumulative report from several major centres in the United States including Baltimore, New York, Watertown, Augusta, California, St Louis, and Washington [5]. A possible explanation for the higher rate of cat sensitization observed in our sample may be related to the higher rate of cat ownership and exposure compared to other urban centers with less animal ownership. Saskatoon has 4433 registered cats as of September 2016 through the City of Saskatoon [6]. However, it was not as prominent as other cities in the surrounding area including Regina who has 4757 [7] registered cats and 39,367 in Calgary [8]. According to a 
Table 2 Population demographics and prevalence of atopy

\begin{tabular}{llll}
\hline & Total & Atopic & Non-atopic \\
\hline $\mathrm{n}$ & 1000 & 455 & 545 \\
Age (years) & & & \\
$\quad$ Mean (SD) & $46.5(18)$ & $41.5(17.8)$ & $50.6(17.2)$ \\
$\quad$ Female n (\%) & $567(56.7)$ & $252(55.4)$ & $315(57.8)$ \\
Diagnoses n (\%) & & & \\
$\quad$ Asthma & $658(66)$ & $355(78)$ & $303(56)$ \\
Cough & $138(14)$ & $33(7)$ & $105(19)$ \\
Dyspnea & $121(12)$ & $33(7)$ & $88(16)$ \\
Rhinitis & $44(4)$ & $16(4)$ & $28(5)$ \\
CF/bronchiectasis & $39(4)$ & $18(4)$ & $21(4)$ \\
\hline
\end{tabular}

Age: paired t test $p<0.0001$, female: Chi squared $p=0.44$, diagnoses: $\mathrm{Chi}$ squared $p<0.0001$

2013 market survey, 57\% of Canadians have a household pet and 35\% of Canadian households own a cat [9]. To our knowledge, this prominent rate of cat allergy has not been documented in a Canadian centre prior to this study.

Our rate of dust mite sensitivity prevalence (22.4\%) was found to be significantly lower than those mentioned at other centres. Knowing that approximately one-third (38.3\%) of the Saskatchewan population is atopic [2], our mite sensitization prevalence can be extrapolated to be significantly lower in the general population. Studies published in Hungary (27.8\%) [10] and 17\% in suburban and $26 \%$ in urban Belgium [11] demonstrate similar rates sensitization in their general population to what we found in Saskatchewan's atopic population. A study performed in the United Kingdom reports a sensitization rate of as high as $82 \%$ to Der $\mathrm{f}$ in their atopic population [12].

The hypothesis that dust mite sensitization in Saskatchewan is comparatively low due to our dry climate is supported by a succession of publications from Australia which studied two cities in New South Wales(NSW) [1315]. All papers included one region with a humid climate and high rates of house dust mite burden and another

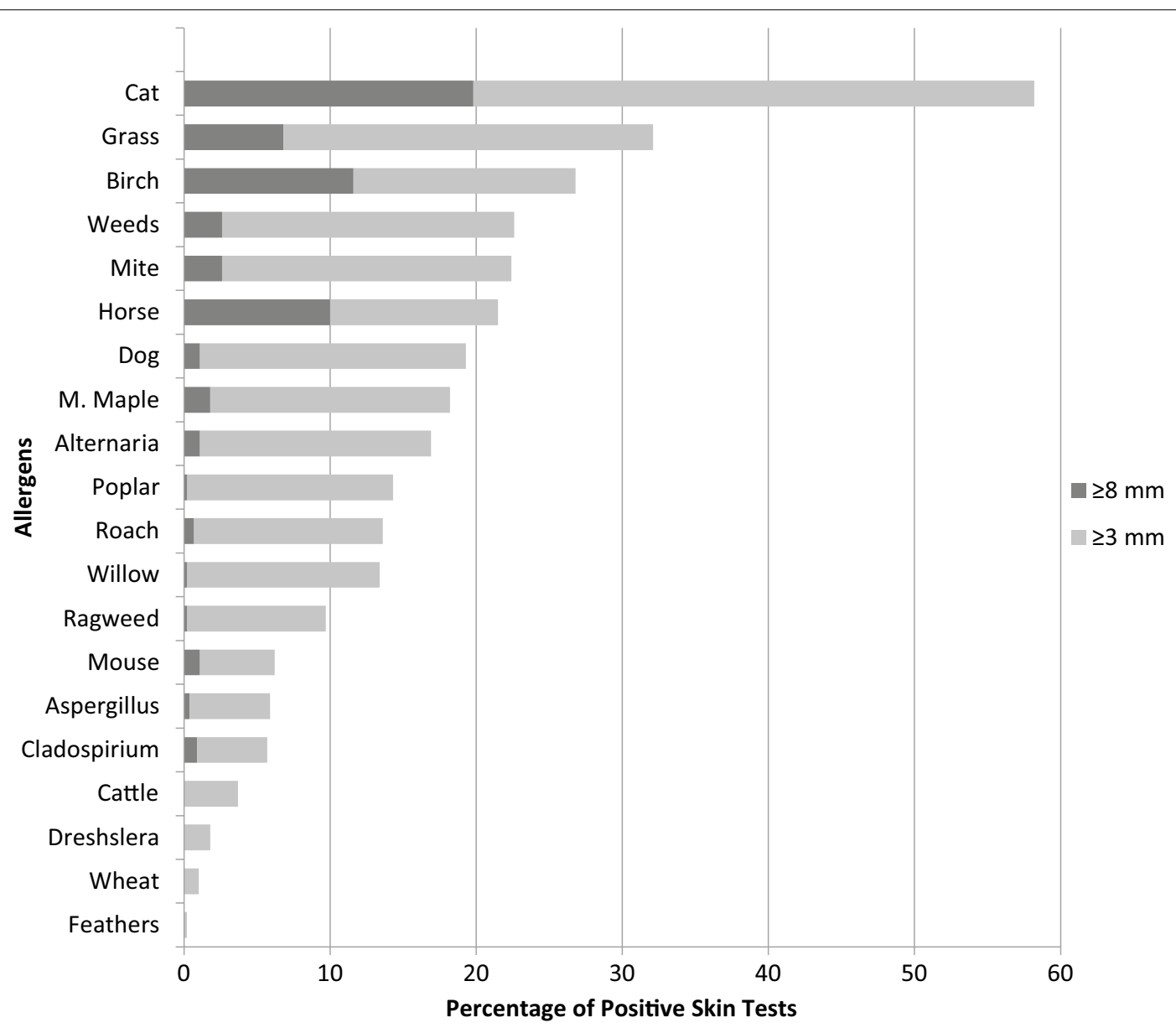

Fig. 1 Profile of sensitization to allergens. A positive epidemiology screen for cat/grass/mite would have incorporated $82.0 \%(n=373)$ of positive skin tests. Those with negative cat/grass/mite responses showed positive responses to trees $(n=34)$, molds $(n=22)$, weeds $(n=7)$, animals $(n=8)$, cockroach $(n=5)$, and feathers $(n=1)$ 
region with a drier climate and lower burden of house dust mite. In the coastal, more humid climate of Lismore, NSW, sensitization rates in the general population were reported to be as high as $33.3 \%$ as compared to $28.3 \%$ in the drier inland city of Wagga Wagga, NSW [14].Wagga Wagga's humidity was reported to be $29-67 \%$ in another paper documenting an $11.3 \%$ sensitization to Der $\mathrm{p}$ in the general population. This was significantly lower when compared to Newcastle, NSW, another coastal city with a humidity of $62-74 \%$ and a reported $20.3 \%$ Der $\mathrm{p}$ sensitivity.

Despite the difference in humidity and burden of mite in Lismore, NSW(humid) vs. Moree/Narrabri, NSW(dry), sensitization rates were similar 28.6 and $26.4 \%$ respectively, however the humid region was associated with more severe bronchial responsiveness despite similar rates of sensitization [13]. This raises the question of whether the rate of markedly positive dust mite skin prick test reactions are lower in dry climates like Saskatchewan (2.6\%) when compared to more humid regions. Unfortunately, the rate of markedly positive reactions is not frequently documented nor is its relationship to humidity, especially for sensitization to dust mite and roach which we know thrive in humid conditions.

The role of mouse allergen has more recently been addressed as an important contributor to non-occupational allergic respiratory disease [16]. Findings in the inner-city asthma study (ICAS) measured sensitization of inner-city school age children with asthma and found $22 \%$ of children had a positive skin test to mouse [16]. Levels of mouse allergen in the home differ substantially with higher rates in inner city dwellings and lower rates in rural areas. [16] Our study found a lower sensitization to mouse which was not surprising as there is a considerable population of rural patients serviced in our health region, however our rates were still quite significant at $6.2 \%$.

The utilization of a cat/grass/mite screening tray (3 individual skin tests) was also analyzed in this study and we found this to have a sensitivity of $82 \%$ for identifying atopy. This is a fairly reasonable sensitivity, however to be used as a screening test a higher sensitivity would be desired. The highest proportion of atopic subjects who failed the screen showed sensitivity to tree ( $44 \%$ of those who failed, $\mathrm{n}=34$ ). Given that birch was found to be the third highest sensitivity, perhaps if repeated a cat/grass/ mite/birch epidemiological screening may have a high enough sensitivity to be used exclusively as a screening test in our health region.

\section{Conclusions}

In summary, a prevalence of atopy was obtained in and around Saskatoon, Saskatchewan. The highest prevalence in this region is to cat dander ( $58.2 \%$ of atopics) which is higher than previously documented in other regions internationally. The rate of dust mite sensitivity $(22.4 \%)$ was found to be lower than those mentioned in other centres and is thought to be secondary to Saskatchewan's dry climate. The prevalence of markedly positive reactions is low $(2.6 \%)$, anecdotally this is thought to be lower than more humid regions such as Eastern Canada. There was a low sensitization to mouse (6.2\%), however this was nonnegligible and certainly an important contributor to nonoccupational allergic respiratory disease. A cat/grass/mite epidemiological screen in our health region was helpful but is not sensitive enough to be used exclusively as a screening test for atopy. This screen may have been more successful in a region with higher rates of mite sensitization.

\section{Abbreviations}

CF: cystic fibrosis; M.Maple: Manitoba Maple; SD: standard deviation; BAU: bioequivalent allergy unit; $\mathrm{AU}$ : allergy units; Der p: Dermatophagoides pteronyssinus (house dust mite); Der f: Dermatophagoides farina (house dust mite).

\section{Authors' contributions}

DWC designed and conducted the study, BED prepared tables and graph, SDL wrote the manuscript. All authors read and approved the final manuscript.

\section{Author details \\ ${ }^{1}$ Department of Internal Medicine, University of Saskatchewan, 103 Hospital Drive, Saskatoon, SK S7N 0W8, Canada. ${ }^{2}$ Division of Respirology, Critical Care and Sleep Medicine, Department of Medicine, University of Saskatchewan, 5th Floor Ellis Hall, 103 Hospital Drive, Saskatoon, SK S7N 0W8, Canada.}

\section{Acknowledgements}

Not applicable.

\section{Competing interests}

The authors declare that they have no competing interests.

Availability of data and materials

All data are contained in the paper.

Consent for publication

We consent for publication of this manuscript.

Ethics approval and consent to participate

Ethics not required for a de-identified chart review, however our patients all sign consent for such chart review.

Received: 18 November 2016 Accepted: 26 January 2017

Published online: 08 February 2017

\section{References}

1. Newson RB, Ree RV, et al. Geographical variation in the prevalence of sensitization to common aeroallergens in adults: GA² LEN survey. Allergy. 2014;69:643-51.

2. Cockcroft DW, Murdock KY, et al. Sensitivity and specificity of histamine $\mathrm{PC}_{20}$ determination in random selection of young college students. J Allergy Clin Immunol. 1992;89(1):23-30.

3. Burney PG, Britton JR, Chinn S, et al. Descriptive epidemiology of bronchial reactivity in an adult population: results from a community study. Thorax. 1987;42(1):38-44.

4. Mallol J, Raby P, Cambiazzo D, et al. Prevalence and allergen sensitization profile in 1199 asthmatic children: consecutive series of cases. Med J Chile. 2014;142:5 
5. Eggleston PA, Rosenstreich D, et al. Relationship of indoor allergen exposure to skin test sensitivity in inner-city children with asthma. Allergy Clin Immunol. 1998;102(4):563-70.

6. City of Saskatoon: animal services, City Hall $2223^{\text {rd }}$ Ave N, Saskatoon.

7. City of Regina: animal licensing program, City Hall 2476 Victoria Avenue. Regina.

8. City of Calgary: animal services centre, 2201 Portland Street SE. Calgary.

9. Pet Ownership is the "Cat's Meow" in Canada. Ipsos public affairs: the social research and corporate reputation specialists; 2013.

10. Sóti $L$, Endre L. Prevalence of the most common respiratory allergens generating positive prick-reaction based on the examination of 2124 children suffering from respiratory allergy between 1992-2000. Orvosi Hetilap. 2005;146(18):833-7.

11. Wieringa MH, Weyler JJ, Bastelaer FJ, et al. Higher asthma occurrence in an urban than a suburban area: role of house dust mite skin allergy. Eur Respir J. 1997;10:1460-6.
12. Peat JK, Tovey E, Mellis CM, Leeder SR, Woolcock AJ. Importance of house dust mite and Alternaria allergens in childhood asthma: an epidemiological study in two climatic regions of Australia. Clin Exp Allergy. 1993;23:812-20.

13. Hendrick DJ, Davies RJ, D'Souza MF, Peys J. An analysis of skin prick test reactions in 656 asthmatic patients. Thorax. 1975;30(1):2-8.

14. Peat JK, Gray EJ, Mellis CM, et al. Differences in airway responsiveness between children and adults living in the same environment: an epidemiological study in two regions in New South Wales. Eur Respir J. 1994;7:1805-13.

15. Britton WJ, Woolcock AJ, Peat JK, et al. Prevalence of bronchial hyperresponsibeness in children: the relationship between asthma and skin reactivity to allergens in two communities. Int J Epidemiol. 1986;15(2):202-9.

16. Matsui EC. Role of mouse allergens in allergic disease. Curr Allergy Asthma Rep. 2009;9:370-5.

\section{Submit your next manuscript to BioMed Central and we will help you at every step:}

- We accept pre-submission inquiries

- Our selector tool helps you to find the most relevant journal

- We provide round the clock customer support

- Convenient online submission

- Thorough peer review

- Inclusion in PubMed and all major indexing services

- Maximum visibility for your research

Submit your manuscript at www.biomedcentral com/submit 